\title{
NETWORK SCIENCE
}

Volume 3

Number 4

\section{CONTENTS}

\section{Articles}

Relative centrality and local community detection

CHENG-SHANG CHANG, CHIH-JUNG CHANG, WEN-TING HSIEH, DUAN-SHIN LEE AND LI-HENG LIOU

Triadic analysis of affiliation networks

JASON CORY BRUNSON

Robustness and modular structure in networks

JAMES P. BAGROW, SUNE LEHMANN AND YONG-YEOL AHN

Further insights into the interareal connectivity of a cortical network

Manuscripts for consideration for Network Science should be submitted electronically, using the Manuscript Central System at http:// journals.cambridge.org/NWS. This system will allow authors to benefit from faster review and earlier, online publication. Authors who are unable to submit online should contact the NWS Editorial Office (at networkscience@ cambridge.org) for assistance. 


\section{EDITORS}

Ulrik Brandes, Computer Science and Mathematics, University of Konstanz, Germany

Noshir Contractor, Communication, Engineering, and Management, Northwestern University, USA

Filippo Menczer, Information Science, Indiana University, USA

Garry Robins, Psychology and Political Science, University of Melbourne, Australia

Jaideep Srivastava, Web Science and Computer Engineering, University of Minnesota, USA

Thomas Valente, Public Health and Medicine, University of Southern California, USA

Fernando Vega-Redondo, Economics, Bocconi University, Italy

Alessandro Vespignani, Physics, Northeastern University, USA

Stanley Wasserman (Coordinating Editor), Statistics and Sociology, Indiana University, USA

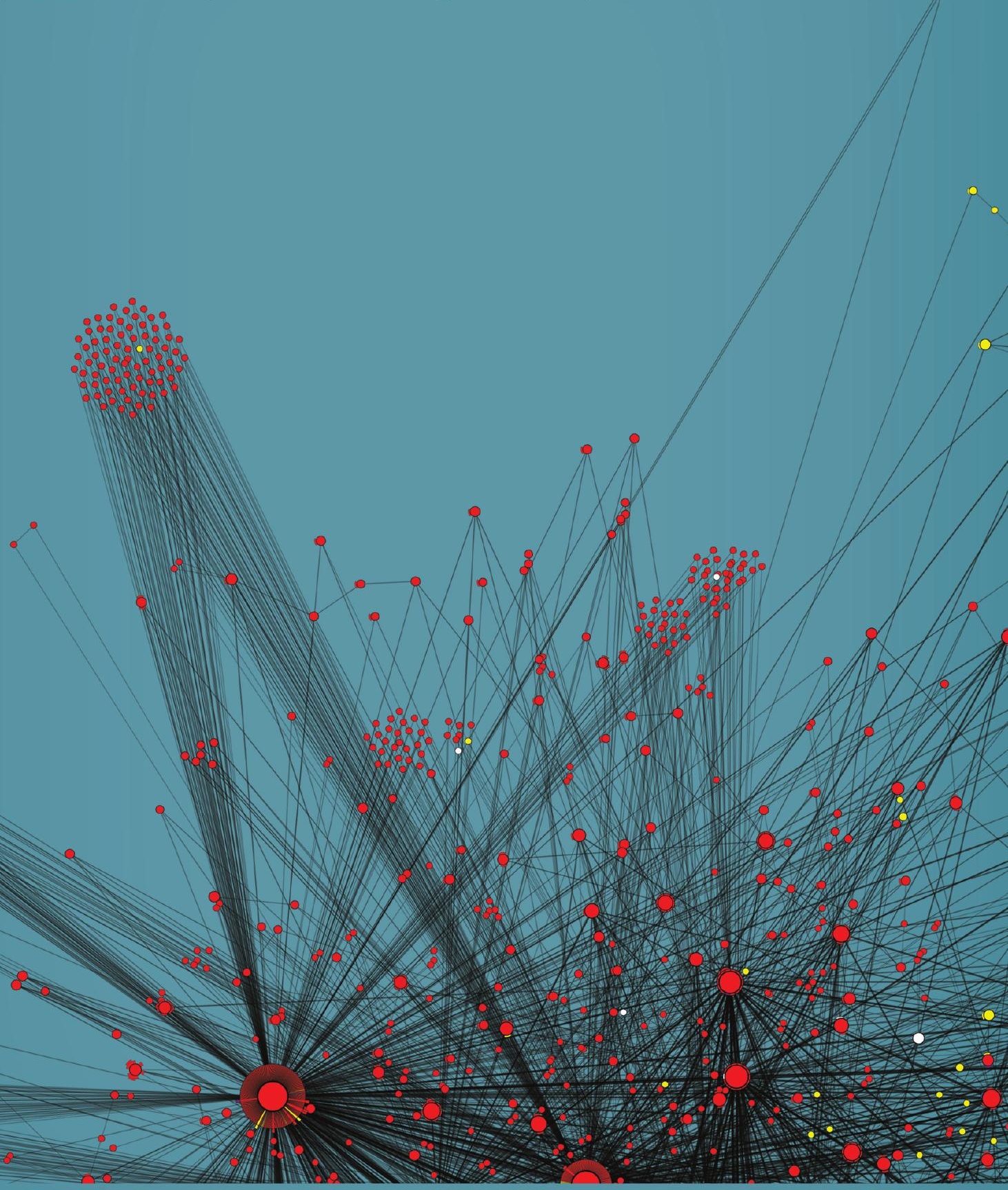

Cambridge Journals Online

For further information about this journal please go to the journal web site at:

journals.cambridge.org/nws 